\title{
Development of Language Proficiency and Pragmatic Competence in an Immersive Language Program
}

\author{
Vahid Rafieyan ${ }^{1 \& 2}$, William Rozycki ${ }^{1}$ \\ ${ }^{1}$ International College of Liberal Arts, Yamanashi Gakuin University, Kofu, Yamanashi, Japan \\ ${ }^{2}$ Department of Comparative Study of Cultures, Tsuru University, Tsuru, Yamanashi, Japan \\ Received: November 1, 2018 \\ Accepted: November 20, $2018 \quad$ Online Published: November 26, 2018 \\ doi:10.5430/wjel.v9n1p10 \\ URL: https://doi.org/10.5430/wjel.v9n1p10
}

\begin{abstract}
Since pragmatic competence and grammatical competence are two distinct aspects of communicative competence (Bachman, 1990), a high level of grammatical competence may not lead to a high level of pragmatic competence; rather, it can be best developed through immersion in the target language. In this respect, this paper addresses three research questions within the context of an immersive language program in an EFL setting: 1) Does instruction in an immersive language program have a significant effect on language learners' general language proficiency? 2) Is there any significant relationship between language learners' general language proficiency and their pragmatic competence? 3) Is there any significant relationship between language learners' level of language contact and their pragmatic competence?

In the experiment, Japanese first-year college students $(n=18)$ were assessed through TOEFL PBT at the start of a one-year language immersion program. The subjects thereupon participated in an intensive language program. At the end of the academic year, all subjects took another TOEFL PBT along with a pragmatic competence test (Bardovi-Harlig, 2009) and a language contact survey. The statistical findings of this study demonstrated a significant positive effect for immersive language program on general language proficiency. However, the findings found no significant association between general language proficiency and pragmatic competence and only a weak correlation between language contact and pragmatic competency. This suggests that developing general linguistic proficiency and immersive language contact with a target language do not automatically ensure the acquisition of pragmatic competence.
\end{abstract}

Keywords: immersive language program, language proficiency, pragmatic competence

\section{Introduction}

Pragmatic competence, defined as the ability to convey one's intention appropriately and to interpret another's intention, explicitly or implicitly stated, in a communicative situation (Thomas, 1995), plays an important role in successful cross-cultural communication (Rafieyan, 2016c; Rafieyan, 2016f). In fact, pragmatic competence should be paid equal attention in language classes as grammatical competence (Jung, 2001). This is because, according to Bachman's (1990) model of communicative competence, pragmatic competence and grammatical competence are two distinct aspects of communicative competence. Consequently, a high level of grammatical competence does not lead to a high level of pragmatic competence, and even language learners at the advanced levels of language proficiency cannot achieve a native-like communicative competence (Bardovi-Harlig \& Dornyei, 1998; Bardovi-Harlig, 2001; Barron, 2003; Liu, 2006; Rose, 2005; Gharaghani et al., 2011). Since pragmatic competence of a language stems from the cultural norms of the speakers of the language, it can be best developed through exposure to that language (Farashaiyan \& Tan, 2012; Roever, 2012).

To scrutinize the actual relationship between grammatical competence and pragmatic competence as well as the relationship between target language exposure and pragmatic competence, a number of researchers in the field of pragmatics conducted a series of studies during the past two decades. The studies conducted so far, however, have had contradictory findings. While some researchers found pragmatic competence develops with language proficiency and language exposure (e.g., Matsumura, 2003; Bardovi-Harlig et al., 2008; Taguchi, 2013; Rafieyan, 2018), some other researchers found that pragmatic competence is not associated with language proficiency and language 
exposure (e.g., Takahashi, 2005; Taguchi, 2008).

In one of these studies, Matsumura (2003) examined the effect of both target language proficiency and exposure to target language on the development of language learners' pragmatic competence. Participants in the study consisted of a group of Japanese learners of English on an eight-month academic exchange program at a university in Canada. Pragmatic competence was measured through a multiple-choice questionnaire focusing on offering advice. Language proficiency was also measured through language learners' scores on TOEFL. Finally, level of exposure to target language was obtained through a self-report questionnaire. The findings of the study revealed that both language proficiency and amount of target language exposure have potential to account for the development of pragmatic competence.

Bardovi-Harlig et al. (2008) were the other researchers who investigated the influence of language proficiency on the development and use of a particular aspect of pragmatic competence referred to as conventional expressions. Participants of their study consisted of a group of language learners from distinct countries in four levels of classes, from low intermediate to low advanced, of an intensive English program at a university in the American Midwest. The study employed a speech production task via a computer-delivered aural discourse completion task. The findings of the study showed that language learners of various native languages often share production strategies and language learners increase their use of conventional expressions at higher levels. These findings clearly indicate that language proficiency is associated with pragmatic competence.

Taguchi (2013) also conducted a study to investigate the effect of language proficiency and exposure to target language on appropriate and fluent production of a particular aspect of pragmatic competence referred to as conventional expressions. Participants in the study included three groups of Japanese learners of English at a university in Japan: a low language proficiency without study abroad experience group, a high language proficiency without study abroad experience group, and a high language proficiency with study abroad experience group. Pragmatic competence was assessed through a computerized oral discourse completion test. The findings of the study suggested that while all learner groups failed to reach a native level, study abroad experience presented an advantage in the appropriate production of conventional expressions whereas language proficiency presented an advantage in speech rates. The findings show that both language proficiency and target language exposure can contribute to the development of pragmatic competence.

Most recently, Rafieyan (2018) examined the association of a particular aspect of pragmatic competence referred to as knowledge of formulaic sequences with language proficiency. Participants of his study were a group of Japanese learners of English as a foreign language at three levels of the intensive English program of a university in Japan: low intermediate, intermediate, and high intermediate. Knowledge of formulaic sequences was assessed through an oral-production discourse completion task developed by Bardovi-Harlig et al. (2015). The analysis of Spearman rank-order correlation coefficient showed a strong positive relationship between language learners' knowledge of formulaic sequences and their level of language proficiency.

Unlike studies conducted by Matsumura (2003), Bardovi-Harlig et al. (2008), Taguchi (2013), and Rafieyan (2018) that found pragmatic competence is positively associated with language proficiency and target language exposure, the studies by Takahashi (2005) and Taguchi (2008) had different findings. Takahashi (2005) investigated the effect of two individual difference variables including motivation and language proficiency on language learners' pragmalinguistic competence. Participants in the study consisted of a group of Japanese learners of English as a foreign language at a college in Japan. Data for the study were collected through a motivation questionnaire, a language proficiency test, and an awareness retrospection questionnaire. The study found that language learners' motivation but not their language proficiency had a significant effect on the development of their pragmalinguistic competence. The findings suggest that a higher level of language proficiency does not automatically lead to a higher level of pragmatic competence.

Taguchi (2008) also conducted a study to explore the influence of target language contact and cognitive processing ability on the development of accurate and speedy comprehension of a particular aspect of pragmatic competence referred to as implied meaning over a period of four-month sojourn in the target language country. Participants were a group of Japanese learners in a college in the United States. Ability to comprehend implied meaning, cognitive processing ability, and the amount of target language contact were respectively assessed through a computerized pragmatic listening test, a lexical access test, and a survey questionnaire. The findings of the study revealed that cognitive processing ability and language contact have significant impact on the speed but not the accurate comprehension of target language implied meaning. These findings further confirm the findings obtained by Takahashi (2005) that there is no relationship between language proficiency and pragmatic competence. The findings 
also indicate that exposure to target language, through studying in the target language country, does not lead language learners to the development of pragmatic competence.

Given the significance of pragmatic competence for successful cross-cultural communication on one hand and the discrepancy over the actual effect of language proficiency and target language exposure on the development of pragmatic competence on the other hand, the current study investigates the effect of instruction in an immersive language program on general language proficiency and whether a high level of general language proficiency and target language contact lead to a high level of pragmatic competence. Therefore, the research questions to be addressed in the study are:

Does instruction in an immersive language program have a significant effect on language learners' general language proficiency?

Is there any significant relationship between language learners' general language proficiency and their pragmatic competence?

Is there any significant relationship between language learners' level of language contact and their pragmatic competence?

Accordingly, the null hypotheses are:

Instruction in an immersive language program has no significant effect on language learners' general language proficiency.

There is no significant relationship between language learners' general language proficiency and their pragmatic competence.

There is no significant relationship between language learners' level of language contact and their pragmatic competence.

\section{Methodology}

\subsection{Participants}

Participants of the study consisted of 18 Japanese learners of English as a foreign language at the International College of Liberal Arts (iCLA) at Yamanashi Gakuin University, Japan. The participants were in three levels of language proficiency of elementary (6), intermediate (7), and advanced (5) in the intensive English program of iCLA. They were all at the first year of their studies. Among the participants, 8 were females and 10 were males. They were all 18 years old. All were required to live in the College's dormitories, sharing units with non-Japanese English speakers from fifty countries. The language used for communication among the dormitory residents and in classes was English.

\subsection{Instruments}

Three types of instruments were used as data collection tools in the current study: a language proficiency test, a discourse completion task, and a language contact survey.

To assess language learners' general language proficiency, Test of English as a Foreign Language (TOEFL) was used. There are two types of TOEFL tests: paper-based (PBT) and internet-based (IBT). For the current study, the paper-based version (PBT) was used. The test consists of three sections: listening comprehension, structure/written expression, and reading comprehension. The total paper-delivered test score is reported on a scale that ranges from 310 to 677 .

To assess language learners' pragmatic competence, a discourse completion task eliciting a variety of speech acts including expressions of gratitude, apologies, warnings, leave-takings, requests, condolences, declining offers, acceptance of a request, acceptance of an invitation, invitation, declining an invitation, an agreement, deflecting thanks, and an introduction developed by Bardovi-Harlig (2009) was adopted. The discourse completion task consisted of 32 scenarios comprising both initiating and responding scenarios. The initiating scenarios $(\mathrm{n}=13)$ required language learners to initiate an interaction and the responding scenarios $(n=19)$ required language learners to respond to an interlocutor's turn.

To assess language learners' level of target language contact, a survey containing four situations outside the classroom in which students could interact with non-Japanese over the course of the past academic year was developed by researchers. The four situations were: 1) dining in the college cafeteria, 2) activities in the dormitories (e.g. parties, conversation with dorm mates etc.), 3) activities away from the college environs (in town, travel, etc.), and 4) electronic communication (gaming, chatting, SNS, email, etc.) 
To assess the validity of the language contact survey, content validity was used. The researchers wrote out the definition of what they wanted to measure and then gave this definition, along with the instrument and a description of the intended sample, to two professors of English at Yamanashi Gakuin University. The professors confirmed that the content and format of the instrument were consistent with the definition of the variable and the sample of objects to be measured (Fraenkel et al., 2012).

\subsection{Procedure}

At the beginning of the academic year, the TOEFL test was administered to all language learners participating in the study. The language learners were then trained in various language skills for the whole academic year ( 30 weeks). During the academic year, language learners took listening, speaking, reading, writing, testing, and content-based classes. At the end of the academic year, another TOEFL test was administered to all the language learners. They were also asked to complete the discourse completion task by writing a brief expression they would say in each situation, and in addition responded to the language contact survey. The results of all tests were recorded for the purpose of data analysis.

\subsection{Data Analysis}

To analyze the effect of instruction on language learners' general language proficiency, paired-samples t-test, in which the dependent variable is measured two or more times for each individual in a single sample (Gravetter \& Wallnau, 2013), was used. To provide an indication of the magnitude of the differences between the performance of language learners on the TOEFL test used as pre-test and the TOEFL test used as post-test, eta squared, which is the most commonly used effect size statistic (Pallant, 2013), was computed. The guidelines for interpreting the eta squared value, as proposed by Cohen (1988), are presented in Table 1. Finally, the graphical presentation of the performance of language learners on TOEFL tests before the intervention and after the intervention was provided.

Table 1. Interpretation of Eta Squared Values

\begin{tabular}{ll}
\hline Value & Effect Size \\
\hline 0.01 & Small Effect \\
0.06 & Moderate Effect \\
0.14 & Large Effect \\
\hline
\end{tabular}

To assess language learners' pragmatic competence, the appropriateness of the responses to the discourse completion task was assessed by one American and one British linguist using a five-point rating scale ranging from one (very poor) to five (excellent). The ratings along with the description for each band on the scale have been provided in Table 2. As there were 32 scenarios, each participant could get a score ranging from 32 to 160. In this respect, language learners who obtained a score between 1 and 32 were placed at the level of 'very poor', language learners who obtained a score between 33 and 64 were placed at the level of 'poor', language learners who obtained a score between 65 and 96 were placed at the level of 'fair', language learners who obtained a score between 97 and 128 were placed at the level of 'good', and language learners who obtained a score between 129 and 160 were placed at the level of 'excellent'.

Table 2. Appropriateness Rating Scale

\begin{tabular}{|c|c|c|}
\hline Rating & Band & Descriptions \\
\hline 5 & Excellent & $\begin{array}{l}\text { Almost perfectly appropriate and effective in the level of directness, politeness and } \\
\text { formality. }\end{array}$ \\
\hline 4 & Good & $\begin{array}{l}\text { Not perfect but adequately appropriate in the level of directness, politeness and } \\
\text { formality. Expressions are a little off from target-like, but pretty good. }\end{array}$ \\
\hline 3 & Fair & $\begin{array}{l}\text { Somewhat appropriate in the level of directness, politeness and formality. Expressions } \\
\text { are more direct or indirect than the situation requires. }\end{array}$ \\
\hline 2 & Poor & Clearly inappropriate. Expressions sound almost rude or too demanding. \\
\hline 1 & Very Poor & Not sure if the target speech act is performed. \\
\hline
\end{tabular}


The degree of agreement between the ratings assigned by the two raters was then assessed through intraclass correlation coefficient, which is a measure of agreement or consensus, where the measurements used are assumed to be parametric (continuous and having normal distribution). Intraclass correlation coefficient represents agreements between two or more raters or evaluation methods on the same set of subjects. The analysis of intraclass correlation coefficient would give a value between 0 and 1 . The interpretation of the values obtained through intraclass correlation coefficient, according to Landis and Koch (1977), are presented in Table 3.

Table 3. Interpretation of Intraclass Correlation Coefficient Values

\begin{tabular}{ll}
\hline Values & Interpretation \\
\hline 0.0 to 0.2 & Poor Agreement \\
0.3 to 0.4 & Fair Agreement \\
0.5 to 0.6 & Moderate Agreement \\
0.7 to 0.8 & Strong Agreement \\
0.9 to 1.0 & Almost Perfect Agreement \\
\hline
\end{tabular}

Table 4 presents the results of the intraclass correlation coefficient analysis. The inter-rater reliability assessed for the responses to the discourse completion task was 0.72 which, according to the guidelines set by Landis and Koch (1977), indicates a strong agreement between the two raters. To obtain a specific score for language learners' pragmatic competence, the ratings by the two raters assigned to the pragmatic competence of each language learner were averaged.

Table 4. Intraclass Correlation Coefficient

\begin{tabular}{lccccccc}
\hline & Intraclass & \multicolumn{2}{c}{ 95\% Confidence Interval } & \multicolumn{3}{c}{ F Test with True Value 0 } \\
\cline { 3 - 8 } & Correlation $^{\mathrm{b}}$ & Lower Bound & Upper Bound & Value & df1 & df2 & Sig \\
\hline Single Measures & $0.56^{\mathrm{a}}$ & 0.12 & 0.81 & 4.48 & 17 & 17 & 0.00 \\
\hline Average Measures & $0.72^{\mathrm{c}}$ & 0.21 & 0.89 & 4.48 & 17 & 17 & 0.00 \\
\hline
\end{tabular}

Two-way mixed effects model where people effect is random and measures effect is fixed.

a. The estimator is the same, whether the interaction effect is present or not.

b. Type A intraclass correlation coefficients using an absolute agreement definition.

c. This estimate is computed assuming the interaction effect is absent, because it is not estimable otherwise.

To assess language learners' level of language contact, responses to a language contact survey (described in Instruments section above) are presented through descriptive statistics. Language learners self-rated their participation in each of the situations on a point scale from 'never' (=zero) to 'always' (=4 points). They also marked whether the interactions were in English (= factor of 1) or in Japanese (= factor of zero). Cases where both languages were checked were assigned a factor of 0.5 . Thus, a student who marked 'sometimes' ( $=2$ points) for an interaction and marked both languages for that situation received a score of 1 point ( 2 points $X 0.5)$; a student who marked 'sometimes' but only checked Japanese as the language for the interaction received zero points ( 2 points X 0$)$. As there were four situations, each language learner could get a score ranging from 0 to 16 . The language learners were then categorized on a four-level scale of low (scores of 0 to 3), below average (scores of 4 to 7), above average (scores of 8 to 12), and high (scores of 13 to 16) based on their scores.

To assess the relationship between language learners' general language proficiency and their pragmatic competence as well as the relationship between language learners' level of language contact and their pragmatic competence, Pearson product-moment correlation coefficient ( $r$ ), which is used to describe the strength and direction of the linear relationship between two continuous variables (Gravetter \& Wallnau, 2013), was computed. Pearson correlation coefficient can only take on values from -1 to +1 . The plus and minus sign in front indicates whether there is a positive correlation (as one variable increases, so too does the other) or a negative correlation (as one variable increases, the other decreases). The size of the absolute value (ignoring the sign) provides an indication of the strength of the relationship. A perfect correlation of +1 or -1 indicates that the value of one variable can be determined exactly by knowing the value on the other variable. On the other hand, a correlation of 0 indicates no 
relationship between the two variables. Knowing the value on one of the variables provides no assistance in predicting the value on the second variable (Pallant, 2013). Cohen (1988) suggests a set of guidelines to interpret the values between 0.00 and 1.00. The guidelines, which have been presented in Table 5, apply whether or not there is a negative sign in front of the $r$ value.

Table 5. Strength of Relationship

\begin{tabular}{ll}
\hline r Value & Interpretation \\
\hline $0.10-0.29$ & Small Correlation \\
$0.30-0.49$ & Medium Correlation \\
$0.50-1.00$ & Large Correlation \\
\hline
\end{tabular}

The squared correlation $\left(\mathrm{r}^{2}\right)$, called the coefficient of determination, was then used to measure the proportion of variability in language learners' pragmatic competence that can be determined from its relationship with their level of language proficiency and language contact. Squared correlation would give a value ranging from 0.00 to 1.00 . Cohen (1988) has also suggested a set of guidelines to interpret the values of squared correlation. The criteria for interpreting the value of squared correlation $\left(\mathrm{r}^{2}\right)$, as proposed by Cohen (1988), are presented in Table 6 .

Table 6. Percentage of Variance Explained, $\mathrm{r}^{2}$

\begin{tabular}{ll}
\hline $\mathbf{r}^{2}$ Value & Interpretation \\
\hline 0.01 & Small Correlation \\
0.09 & Medium Correlation \\
0.25 & Large Correlation \\
\hline
\end{tabular}

\section{Findings}

\subsection{Effect of Instruction in an Immersive Language Program on General Language Proficiency}

Table 7 presents the results of paired-samples t-test. To check whether instruction in an immersive language program had a significant effect on language learner's language proficiency, the final column labeled Sig. (2-tailed) should be considered. This is the probability ( $\mathrm{p}$ ) value. If this value is equal to or less than $0.05(\mathrm{p} \leq 0.05)$, there is a significant difference between the two scores. However, if the value is larger than $0.05(\mathrm{p}>0.05)$, there is a nonsignificant difference between the two scores (Pallant, 2013). In this study, the probability value is 0.00 which is substantially smaller than the specified alpha value of 0.05 . Therefore, there is a significant difference in language learners' language proficiency level before and after the treatment.

Table 7. Paired Samples Test

\begin{tabular}{|c|c|c|c|c|c|c|c|c|}
\hline & \multicolumn{5}{|c|}{ Paired Differences } & \multirow[b]{3}{*}{$\mathrm{t}$} & \multirow[b]{3}{*}{ df } & \multirow[b]{3}{*}{$\begin{array}{l}\text { Sig. } \\
\text { (2-taile } \\
\text { d) }\end{array}$} \\
\hline & \multirow[b]{2}{*}{ Mean } & \multirow[b]{2}{*}{$\begin{array}{c}\text { Std. } \\
\text { Deviation }\end{array}$} & \multirow[b]{2}{*}{$\begin{array}{l}\text { Std. Error } \\
\text { Mean }\end{array}$} & \multicolumn{2}{|c|}{$\begin{array}{c}95 \% \text { Confidence Interval of } \\
\text { the Difference }\end{array}$} & & & \\
\hline & & & & Lower & Upper & & & \\
\hline Pre-test - Post-test & -99.94 & 26.55 & 6.25 & -113.14 & -86.74 & -15.97 & 17 & 0.00 \\
\hline
\end{tabular}

Having established that there is a significant difference, the next step is to find out which set of scores is higher (pre-test or post-test). To do this, the first box in Table 8 should be considered. This box gives the mean scores for each of the two sets of scores. In this case, the mean of pre-test was 398.06 and the mean of post-test was 498.00 . Therefore, it is concluded that there was a significant improvement in language learners' language proficiency from pre-test (prior to the intervention) to post-test (after the intervention). 
Table 8. Paired Samples Statistics

\begin{tabular}{lcccc}
\hline & Mean & N & Std. Deviation & Std. Error Mean \\
\hline Pre-test & 398.06 & 18 & 30.30 & 7.14 \\
Post-test & 498.00 & 18 & 31.87 & 7.51 \\
\hline
\end{tabular}

Although the results show a significant effect of intervention on language learners' language proficiency, it does not tell much about the magnitude of the intervention's effect. To do this, eta squared, which is the most commonly used effect size statistic (Pallant, 2013), was calculated. Eta squared can be obtained using the following formula:

$$
\text { Eta squared }=\frac{t^{2}}{t^{2}+(N-1)}
$$

Putting the data into the formula will give us:

$$
\text { Eta squared }=\frac{(-15.97)^{2}}{(-15.97)^{2}+(18-1)}=0.94
$$

The effect size is 0.94 which, according to the guidelines proposed by Cohen (1988), represents an extremely large effect. Expressed as a percentage $(0.94 \times 100=94), 94$ percent of the variance in language learners' general language proficiency is explained by language instruction in an immersive language program. A graphical presentation of the performance of language learners on the pre-test and post-test is depicted in Figure 1.

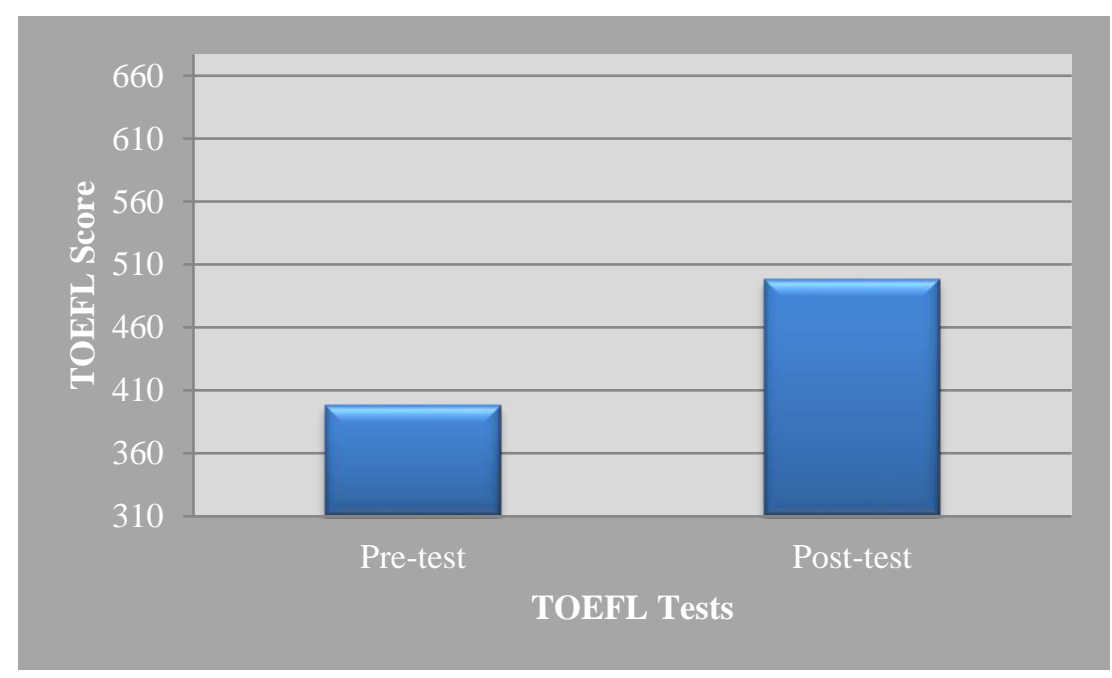

Figure 1. Performance of Language Learners before and after Intervention

\subsection{Relationship between General Language Proficiency and Pragmatic Competence}

Table 9 presents a descriptive presentation of pragmatic competence for language learners participating in the study. Descriptive data presented in the table consists of the number and percentage of participants for each level of pragmatic competence. According to the descriptive data, all participants presented their pragmatic competence at a satisfactory level. As the data shows, 11.1 percent of participants presented their pragmatic competence at the excellent level, 61.1 percent of participants presented their pragmatic competence at the good level, and 27.8 percent of participants presented their pragmatic competence at the fair level. None of the participants, however, presented their pragmatic competence at the poor or very poor levels. 
Table 9. Descriptive Presentation of Language Learners' Pragmatic Competence

\begin{tabular}{lcc}
\hline Pragmatic Competence & Number of Participants & Percentage of Participants \\
\hline Excellent & 2 & $11.1 \%$ \\
Good & 11 & $61.1 \%$ \\
Fair & 5 & $27.8 \%$ \\
Poor & 0 & $00.0 \%$ \\
Very poor & 0 & $00.0 \%$ \\
\hline
\end{tabular}

Table 10 presents the results of Pearson product-moment correlation coefficient (r) analysis between language learners' general language proficiency on the post-test and their pragmatic competence. The first thing to consider is the direction of the relationship between the variables (general language proficiency and pragmatic competence). The data shows that there is a positive relationship between the two variables, that is, the higher the general language proficiency, the higher the pragmatic competence. The second thing to consider is the size of the value of the correlation coefficient to indicate the strength of the relationship between the two variables (general language proficiency and pragmatic competence). The value of correlation coefficient obtained in the analysis of Pearson product-moment correlation coefficient (r) is 0.04 which, according to the guidelines proposed by Cohen (1988) to interpret the values of correlation coefficient, suggests no relationship between general language proficiency and pragmatic competence.

Table 10. Correlations

\begin{tabular}{llcc}
\hline & & $\begin{array}{c}\text { General Language Proficiency } \\
\text { (Post-test) }\end{array}$ & Pragmatic Competence \\
\hline General Language Proficiency & Pearson Correlation & 1 & 0.04 \\
(Post-test) & Sig. (2-tailed) & & 0.85 \\
& $\mathrm{~N}$ & 18 & 18 \\
\hline Pragmatic Competence & Pearson Correlation & 0.04 & 1 \\
& Sig. (2-tailed) & 0.85 & 18 \\
& $\mathrm{~N}$ & 18 & 18 \\
\hline
\end{tabular}

\subsection{Relationship between Level of Language Contact and Pragmatic Competence}

Table 11 presents the descriptive presentation of level of language contact for language learners participating in the study. Descriptive data presented in the table consists of the number and percentage of participants for each level of pragmatic competence. According to the descriptive data, the majority of participants presented their level of target language contact at less than average level. As the data shows, none of participants presented their level of target language contact at the high level, 33.3 percent of participants presented their level of target language contact at the above average level, 61.1 percent of participants presented their level of target language contact at below average level, and 5.6 percent of the participants presented their level of target language contact at low level.

Table 11. Descriptive Presentation of Language Learners' Level of Language Contact

\begin{tabular}{lcc}
\hline Level of Language Contact & Number of Participants & Percentage of Participants \\
\hline High & 0 & $00.0 \%$ \\
Above Average & 6 & $33.3 \%$ \\
Below Average & 11 & $61.1 \%$ \\
Low & 1 & $05.6 \%$ \\
\hline
\end{tabular}

Table 12 presents the results of Pearson product-moment correlation coefficient (r) analysis between language learners' level of language contact and their pragmatic competence. Again, the first thing to consider in correlation analysis is the direction of the relationship between the variables (level of language contact and pragmatic 
competence). The data shows that there is a positive relationship between the two variables, that is, the higher the general language proficiency the higher the pragmatic competence. The second thing to consider in correlation analysis is the size of the value of the correlation coefficient. This value will indicate the strength of the relationship between the two variables (level of language contact and pragmatic competence). The value of correlation coefficient obtained in the analysis of Pearson product-moment correlation coefficient (r) is 0.21 which, according to the guidelines proposed by Cohen (1988), suggests a small relationship between level of language contact and pragmatic competence.

Table 12. Correlations

\begin{tabular}{llcc}
\hline & & Level of Language Contact & Pragmatic Competence \\
\hline Level of Language Contact & Pearson Correlation & 1 & 0.21 \\
& Sig. (2-tailed) & & 0.39 \\
& $\mathrm{~N}$ & 18 & 18 \\
\hline Pragmatic Competence & Pearson Correlation & 0.21 & 1 \\
& Sig. (2-tailed) & 0.39 & 18 \\
& $\mathrm{~N}$ & 18 & 18 \\
\hline
\end{tabular}

To get an idea of how much variance the two variables (level of language contact and pragmatic competence) share, the coefficient of determination was calculated. This can be obtained by squaring the correlation value. The coefficient of determination for the obtained correlation analysis is $\mathrm{r}^{2}=(0.21)^{2}=0.04$ which suggests a small correlation coefficient. To convert the value of coefficient of determination to 'percentage of variance', it is multiplied by 100 , that is, $\mathrm{r}^{2}=(0.21)^{2} \times 100=04$. This suggests that level of language contact helps to explain only 4 percent of the variance in language learners' pragmatic competence.

\section{Discussion}

The study found that the immersive language program had a significant effect on improving language learners' general language proficiency. Language learners who were trained in the immersive language program experienced a significant improvement in their TOEFL scores following the intervention. Therefore, the first null hypothesis of the study, which states that instruction in an immersive language program has no significant effect on language learners' general language proficiency, is rejected. The study also found that there was no correlation between language learners' general language proficiency and their pragmatic competence. Language learners at higher levels of language proficiency did not necessarily possess a higher level of pragmatic competence than language learners who were at lower levels of language proficiency. Therefore, the second null hypothesis of the study, which states that there is no significant relationship between language learners' general language proficiency and their pragmatic competence, is confirmed. Finally, the study found a small correlation between level of language contact and pragmatic competence. Language learners who had more contact with target language speakers did not necessarily possess a higher level of pragmatic competence than language learners who had less contact with target language speakers. Therefore, the third null hypothesis of the study, which states that there is no significant relationship between language learners' level of language contact and their pragmatic competence, is also confirmed.

Significant improvement of language learners' general language proficiency can be attributed to the effectiveness of creating an immersive, residential language learning environment in a foreign language context. In this target language input-rich environment, language learners were immersed in the target language every day for twenty-four hours a day. In this immersive environment, they received intensive language instruction focusing on each specific language skill by expert teachers, were provided with language advising sessions in the Language Acquisition Center, and lived in shared units in the dormitory with international students. They shared social events with international students, who communicated primarily using English. All of these factors could have contributed to their significant success rate within one academic year. In fact, constant language support and target language interaction in this immersive environment may be offering an even better environment than merely living in the target language country where language learners might not receive much support or might not interact with target language speakers because of reticence and other factors.

The lack of correlation between general language proficiency and pragmatic competence can be attributed to the fact that, according to Bachman's (1990) model of communicative competence, pragmatic competence and grammatical 
competence are two distinct aspects of communicative competence. Therefore, a high level of grammatical competence cannot essentially ensure a high level of pragmatic competence (Bardovi-Harlig \& Dornyei, 1998; Bardovi-Harlig, 2001; Barron, 2003; Liu, 2006; Rose, 2005; Gharaghani et al., 2011). It seems that the mere instruction of linguistic aspects of language, such as structure and vocabulary, does not equip language learners with the pragmatic aspects of language. Language learners should be trained in the pragmatic aspects of a target language, in addition to other linguistic aspects.

The small correlation between level of language contact and level of pragmatic competence can be explained through the fact that the learning of pragmatic knowledge takes place in a variety of times and places both inside and outside the classroom; that this learning does not necessarily correspond to interaction with target language speakers during intensive study of language; and that some individuals have gained considerable pragmatic knowledge even before entering an intensive classroom-based study of language. The other factor explaining the low correlation between level of language contact and level of pragmatic competence can be lack of pragmatic instruction. Since language learners participating in the study did not receive any training in pragmatic competence, their awareness of pragmatic features of the target language was not highly developed. As a result, despite constant interaction with target language speakers, the pragmatic features of the target language might have gone unnoticed.

The findings obtained in the current study are in line with the findings obtained by Takahashi (2005) that language learners' motivation, but not their language proficiency, had a significant effect on the development of their pragmalinguistic awareness. The findings obtained in the current study are also consistent with the findings obtained by Taguchi (2008) who found that language contact has no significant impact on the accurate comprehension of target language implied meaning. The findings of the study, however, do not support the findings obtained by Matsumura (2003) and Taguchi (2013) who found that a higher level of contact with target language speakers and a higher level of language proficiency is associated with a higher pragmatic competence. Also, the findings obtained in the study are not consistent with the findings obtained by Bardovi-Harlig et al. (2008) and Rafieyan (2018) who found a strong association between language proficiency and pragmatic competence.

\section{Conclusion}

The study investigated the effect of instruction on general language proficiency, the relationship between general language proficiency and pragmatic competence, and the relationship between level of language contact and pragmatic competence. The findings of the study suggested that intervention in an immersive residential language program has a significant effect on the development of general language proficiency. However, there is no relationship between general language proficiency and pragmatic competence, and there is no significant relationship between level of language contact and pragmatic contact. Language learners participating in the study managed to develop their level of general language proficiency significantly within one academic year. However, this development in their level of general language proficiency and their contact with target language speakers did not develop their level of pragmatic competence. These findings suggest that developing language proficiency and mere immersion in a target language does not develop pragmatic competence. Therefore, in order to develop pragmatic competence in language learners, classroom instruction should be equipped with pragmalinguistic and sociopragmatic features of the target language (Rafieyan, 2016a; Rafieyan, 2016b; Rafieyan, 2016d; Rafieyan, 2016e).

\section{References}

Bachman, L. F. (1990). Fundamental Considerations in Language Testing. Oxford: Oxford University Press.

Bardovi-Harlig, K. (2001). Empirical Evidence of the Need for Instruction in Pragmatics. In K. R. Rose, \& G. Kasper (Eds.), Pragmatics in Language Teaching (pp. 13-32). Cambridge: Cambridge University Press. https://doi.org/10.1017/CBO9781139524797.005

Bardovi-Harlig, K. (2009). Conventional Expressions as a Pragmalinguistic Resource: Recognition and Production of Conventional Expressions in L2 Pragmatics. Language Learning, 59(4), 755-795. https://doi.org/10.1111/j.1467-9922.2009.00525.x

Bardovi-Harlig, K., \& Dornyei, B. (1998). Do Language Learners Recognize Pragmatic Violations? Pragmatic versus Grammatical Awareness in Instructed L2 Learning. TESOL Quarterly, 32(2), 233-259. https://doi.org/10.2307/3587583

Bardovi-Harlig, K., \& Mahan-Taylor, R. (2003). Teaching Pragmatics. Washington DC: U.S. Department of State Office of English Language Programs. 
Bardovi-Harlig, K., Rose, M., \& Nickels, E. L. (2008). The Use of Conventional Expressions of Thanking, Apologizing, and Refusing (Selected Proceedings of the 2007 Second Language Research Forum, ed. Melissa Bowles et al., 113-130). Somerville, MA: Cascadilla Proceedings. istep:

Bardovi-Harlig, K., Mossman, S., \& Vellenga, H. E. (2015). The Effect of Instruction on Pragmatic Routines in Academic Discussion. Language Teaching Research, 19(3), 324-350. https://doi.org/10.1177/1362168814541739

Barron, A. (2003). Acquisition in Interlanguage Pragmatics: Learning How to Do Things with Words in a Study Abroad Context. Amsterdam: Benjamins. https://doi.org/10.1075/pbns.108

Cohen, J. (1988). Statistical Power Analysis for the Behavioral Sciences. Hillsdale, NJ: Lawrence Erlbaum Associates.

Fraenkel, J. R., Wallen, N. E., \& Hyun, H. H. (2012). How to Design and Evaluate Research in Education (8th ed.). New York: McGraw-Hill.s:

Farashaiyan, A., \& Tan, K. H. (2012). On the Relationship between Pragmatic Knowledge and Language Proficiency among Iranian Male and Female Undergraduate EFL Learners. The Southeast Asian Journal of English Language Studies, 18(1), 33-46.

Gharaghani, Z., Eslami Rasekh, A., Dabaghi, A., \& Tohidian, I. (2011). Effect of Gender on Politeness Strategies in Greetings of Native Speakers of Persian; English and EFL learners. Cypriot Journal of Educational Sciences, 3, 93-117.

Gravetter, F. J., \& Wallnau, L. B. (2013). Statistics for the Behavioral Sciences. Belmont, CA: Wadsworth Publishing.

Jung, J. Y. (2001). Issues in Acquisitional Pragmatics. Working Paper in TESOL and Applied Linguistics, Teacher's College, Columbia University.

Landis, J. R., \& Koch, G. G. (1977). The Measurement of Observer Agreement for Categorical Data. Biometrics, 33(1), 159-174. https://doi.org/10.2307/2529310

Liu, J. (2006). Measuring Interlanguage Pragmatic Knowledge of EFL Learners. Frankfurt am Main: Peter Lang.

Matsumura, S. (2003). Modelling the Relationships among Interlanguage Pragmatic Development, L2 Proficiency, and Exposure to L2. Applied Linguistics, 24(4), 465-491. https://doi.org/10.1093/applin/24.4.465

Pallant, J. (2013). SPSS Survival Manual: A Step by Step Guide to Data Analysis Using SPSS Program (5th ed.). Australia: Allen \& Unwin.

Rafieyan, V. (2016a). Relationship between Pragmatic Comprehension and Translation of Culture-Bound Texts. Journal of Applied Linguistics and Language Research, 3(3), 257-267.

Rafieyan, V. (2016b). Effect of Cultural Distance on Pragmatic Comprehension and Production. Advances in Language and Literary Studies, 7(4), 25-32.

Rafieyan, V. (2016c). Relationship between Language Learners' Attitudes toward Cultural Instruction and Pragmatic Comprehension and Production. Advances in Language and Literary Studies, 7(4), 68-75.

Rafieyan, V. (2016d). Effect of Pragmatic Instruction versus Educational Sojourn on Knowledge of Conventional Expressions. International Journal of Learning and Development, 6(2), 1-12. https://doi.org/10.5296/ijld.v6i2.9403

Rafieyan, V. (2016e). Bridging Pragmatic Gap in Translation Process through Developing Pragmatic Awareness. Journal for the Study of English Linguistics, 4(1), 98-110. https://doi.org/10.5296/jsel.v4i1.9667

Rafieyan, V. (2016f). Effect of 'Focus on Form' versus 'Focus on Forms' Pragmatic Instruction on Development of Pragmatic Comprehension and Production. Journal of Education and Practice, 7(20), 41-48.

Rafieyan, V. (2018). Knowledge of Formulaic Sequences as a Predictor of Language Proficiency. International Journal of Applied Linguistics \& English Literature, 7(2), 64-69. https://doi.org/10.7575/aiac.ijalel.v.7n.2p.64

Roever, C. (2012). What Learners Get for Free: Learning of Routine Formulae in ESL and EFL Environments. ELT Journal, 66(1), 10-21. https://doi.org/10.1093/elt/ccq090

Rose, K. R. (2005). On the Effects of Instruction in Second Language Pragmatics. System, 33(3), 385-399. https://doi.org/10.1016/j.system.2005.06.003 
Taguchi, N. (2008). Cognition, Language Contact, and the Development of Pragmatic Comprehension in a Study-Abroad isep.CContext. Language Learning, 58(1), 33-71. https://doi.org/10.1111/j.1467-9922.2007.00434.x

Taguchi, N. (2012). Context, Individual Differences and Pragmatic Competence. Bristol: Multilingual Matters.

Taguchi, N. (2013). Production of Routines in L2 English: Effect of Proficiency and Study-Abroad Experience. System, 41(1), istep:109-121. https://doi.org/10.1016/j.system.2013.01.003

Takahashi, S. (2005). Noticing in Task Performance and Learning Outcomes: A Qualitative Analysis of Instructional Effects in Interlanguage Pragmatics. System, 33(3), 437-461. https://doi.org/10.1016/j.system.2005.06.006

Thomas, J. (1995). Meaning in Interaction: An Introduction to Pragmatics. London: Longman. istep 